University of Nebraska - Lincoln

DigitalCommons@University of Nebraska - Lincoln

Faculty Publications: Department of Teaching, Department of Teaching, Learning and Teacher Learning and Teacher Education

2020

Intercultural Competence in Pre-Service Teacher Candidates

Joan Barnatt

Lisa Andries D'Souza

Ann Marie Gleeson

Kara Mitchell Viesca

Jessica Wery

Follow this and additional works at: https://digitalcommons.unl.edu/teachlearnfacpub

Part of the Curriculum and Instruction Commons, and the Teacher Education and Professional

Development Commons

This Article is brought to you for free and open access by the Department of Teaching, Learning and Teacher Education at DigitalCommons@University of Nebraska - Lincoln. It has been accepted for inclusion in Faculty Publications: Department of Teaching, Learning and Teacher Education by an authorized administrator of DigitalCommons@University of Nebraska - Lincoln. 


\title{
Intercultural Competence in Pre-Service Teacher Candidates
}

\author{
Joan Barnatt, ${ }^{1}$ Lisa Andries D’Souza, ${ }^{2}$ Ann Marie Gleeson, ${ }^{3}$ \\ Kara Mitchell Viesca, ${ }^{4}$ and Jessica Wery ${ }^{5}$
}

\author{
1 Elon University, Elon, NC \\ 2 Assumption College, Worcester, MA \\ 3 Independent Scholar, Newton, MA \\ 4 University of Nebraska-Lincoln, Lincoln, NE \\ 5 University of North Carolina, Chapel Hill, NC \\ Corresponding author - Joan Barnatt, Elon University, CB 2105, Mooney Building, \\ Elon, NC 27244, USA. Email: jbarnatt@elon.edu \\ ORCID \\ Joan Barnatt https://orcid.org/0000-0003-0275-6832 \\ Jessica Wery https://orcid.org/0000-0002-7850-0852
}

\begin{abstract}
This mixed-method study utilizes survey and interview data reflecting teacher candidates' beliefs about intercultural competence to identify areas of targeted support in teacher preparation. Intercultural competence is operationalized by performance on the Cultural Intelligence Survey (CQS) identifying relative areas of strength and weakness in four dimensions. Participants reported awareness of cultural differences and motivation to interact with those from other cultures, with less confidence in their knowledge base and ability to adapt behavior in intercultural interactions. Qualitative data provided explanatory support for understanding how program elements influenced intercultural competence along a developmental trajectory of learning.
\end{abstract}

Keywords: intercultural competence, cultural intelligence, teacher preparation, pre-service preparation

Published in International Journal of Educational Reform 2020, Vol. 29(3), pp 211-235. DOI:10.1177/1056787919896866

Copyright (C) 2019 Joan Barnatt, Lisa Andries D’Souza, Ann Marie Gleeson, Kara Mitchell Viesca, and Jessica Wery. Published by SAGE Publications. Used by permission. 
In a world that is said to be flat (Darling-Hammond, 2015), shrinking (Carreira \& Kagan, 2018), interconnected (Kahn \& Agnew, 2017), and globalized (Hansen, 2017), educators puzzle over ways to effectively reach an increasingly diverse student population. The rise of nativism across the world juxtaposed against widespread intercultural mobility, communication, and evolving technology (Kohli et al., 2017) illustrates complex tensions in an increasingly interconnected world that play out in the classroom. Increasingly, effective teachers must possess intercultural competence in working with children who bring diverse life experiences in terms of language, culture, race, ethnicity, religion, and socio-economic strata (Scanlan \& López, 2014). While there is little doubt that teacher preparation should attend to intercultural competence, there is less certainty about what this might entail or how best to approach this preparation.

In response to increased diversity in K-12 classrooms, teacher preparation programs have implemented a range of opportunities and experiences to address intercultural competence. The literature reflects these efforts, reporting on the relative effectiveness of courses broadly addressing diversity (Allen \& Hancock, 2017; Cole et al., 2011), courses specifically focused on particular populations such as multilingual learners (Baecher, 2012; Samson \& Collins, 2012) and world language experiences in higher education (Tomalin \& Stempleski, 2013; Tran, 2015). Likewise, there is continued and growing interest in program efforts to address diversity through service learning experiences ( $\mathrm{Bu}-$ tin, 2010; Lindahl et al., 2018) and short- and long-term study abroad experiences (He et al., 2017; Twombly et al., 2012). A challenge, however, has been the limited means of assessing intercultural competence in the educational context.

\section{Questions}

This mixed-methods study seeks to assess the influence of the various teacher preparation elements made available to teacher candidates to support intercultural competence. Specifically, our purpose was to identify the extent to which teacher candidates demonstrate intercultural competence, as operationalized by performance on the Cultural Intelligence Survey (CQS) (Ang et al., 2007; 2015), a tool that 
has offered promise in other fields to assess intercultural competence but has yet to be widely utilized in an educational setting. We ask the following questions:

- What are the relative strengths and weaknesses demonstrated by teacher candidates across the CQS dimensions?

- What learning experiences influence teacher candidates' cultural intelligence?

The first question underscores the potential for the CQS in identifying relative areas of strength or weakness related to cultural intelligence among teacher candidates to provide teacher educators with a means of differentiating instruction to the needs of teacher candidates. The second question provides explanatory evidence for CQS outcomes and acts as an indicator of the kinds of opportunities teacher candidates need.

\section{Theory}

\section{Intercultural Competence}

This mixed-methods study is grounded in the conceptual understanding of intercultural competence as a means of "managing interaction[s] in ways that are likely to produce more appropriate and effective individual, relational, group, or institutional outcomes" (Deardorff, 2009, p. 6). The literature offers several models of intercultural competence, also referred to as cultural competence, multicultural competence, intercultural maturity, and intercultural sensitivity (Fantini, 2009). Differences in defining intercultural competence reveal disciplinary lines (Spitzberg \& Changnon, 2009), reflecting the various ways intercultural competence might manifest depending on the particular field (Deardorff \& Arasaratnam-Smith, 2017).

Despite lack of consensus, Bennett (2004) notes there is general agreement the concept includes: knowledge and skills encompassing cognitive, affective and behavioral factors, applicable across cultural contexts, that result in positive and effective interactions with others. In a multi-disciplinary review of the literature on cultural competence, 
Alizadeh and Chavan (2016) similarly concluded that three major elements exist across the models, including: cultural awareness, knowledge and skills (p. 118). These models, however, are generally grounded in the fields of business and healthcare rather than education. Of the eighteen models assessed by Alizadeh and Chavan (2016), only Deardorff's (2006) Process Model of Intercultural Competence was specifically grounded in an educational context, that of higher education. Deardorff and Arasaratnam-Smith (2017) subsequently emphasizes that intercultural competence is an ongoing process requiring multiple experiences and self-reflection; is characterized by criticalthinking skills; is founded on attitudes of openness, curiosity and respect; and requires the ability to see from another's point of view. While assessing these factors remains elusive, providing university students with opportunities to address these dispositions and skills promotes the growth of intercultural competence.

In the literature and in practice, the study of cultural diversity in the K-12 educational context is most often represented in multicultural theory (Banks, 2015; Gay, 2018), culturally relevant/responsive teaching (Aronson \& Laughter, 2016; Ladson-Billings, 2004; 2014), education of multilingual learners (Athanases et al., 2012; Cochran-Smith et al., 2016), global or international education (Kopish, 2016; Merryfield et al., 2008). Here, teachers and teacher educators are called upon to utilize the strengths of culture to develop positive educational environments, foster learning, and enrich the life opportunities of all students. Cultural competence has been identified as one of three factors central to Culturally Relevant Teaching and Pedagogy, Ladson-Billings, 2004, 2014) seminal conceptualization of successful practice of successful teachers of African American learners, now expanded to more broadly encompass a range of ethnic and racial groups.

As with any field, intercultural competence in teacher preparation is generally addressed across the spectrum of university programs through curriculum or programming (Deardorff, 2011). That is, students may complete one or more courses with a cultural or international dimension or take part in experiences designed to include an intercultural element. The latter may include on-campus programs, service-learning opportunities, or education abroad and encompass a range of experiences with very different potential for promoting intercultural competence. In fact, only a very small percentage of the 
general university population face requirements beyond world language courses that would address such issues (Bok, 2009). Licensure programs in teacher preparation increasingly include a course in issues of diversity and social justice; multiculturalism and culturally relevant teaching; and cultural and language diversity among multilingual learners. Despite this, there remains a dearth of research addressing the assessment of cultural competence.

\section{Methods}

An explanatory sequential mixed-methods approach (Creswell \& Clark, 2017), consistent with the development, data collection and analysis of quantitative data from the CQS, followed by undertaking and analysis of semistructured interviews with selected participants. The CQS responses were utilized in directing the qualitative stage of the study, through refinement of questions in the interviews, selection of participants based on survey responses. Charmaz's (2014) constructivist grounded theory was utilized to provide opportunity to "give voice" to participants which is limited in the survey responses. We viewed this as an opportunity to elicit feelings, assumptions and interpretations made by participants that would be otherwise left unreported. Informed by this approach, we avoided predetermined categories of systematic or emerging grounded theory approaches as a means of allowing for unexpected, unexplored, or previously unrecognized areas that were reported as significant in supporting cultural competence in preparation programs. In using a system of coding, however, we aimed to maintain a rigorous analysis procedure. In triangulating the elements of the study, we sought evidence to support survey data; uncover dissonance between responses and explanations or interpretations that spoke to these differences and; additive information provided in the interviews that were not subject to questions provided in the survey. In total, the value of mixed-methods research provides different lenses to approach complex issues where a single approach could not be expected to provide the same evidence. Mixed-methods also provides added confidence in the results and conclusions drawn, over those in a single approach (McKim, 2017). 


\section{Cultural Intelligence Survey}

Tools for assessing teachers' intercultural competence remain elusive. One promising assessment developed by Ang and Van Dyne (2015), the Cultural Intelligence Survey (CQS), purports to measure cultural intelligence or, "multiple aspects of intercultural competence in a single instrument, based on a theoretically grounded, comprehensive and coherent framework" (p. 10). Cultural intelligence (CQ) refers to the ability to function effectively across a variety of cultural contexts (Ang \& Van Dyne, 2015), which suggests potential flexibility required for a teacher interacting with children and families from an array of cultures. As such, CQ reflects the ability for teachers to step beyond their own cultural space to "navigate culturally complex situations" (Goh, 2012, p. 396) in today's globally impacted classrooms.

The CQS is conceptualized through 4 dimensions - Metacognition, Cognition, Motivation and Behavior (Ang \& Van Dyne, 2015) - making CQ a multidimensional construct. Metacognitive CQ refers to the processes individuals use to acquire and understand cultural knowledge. This CQ gives individuals the awareness and ability to plan for cultural differences. Cognitive CQ demonstrates an understanding of the norms and practices within different cultures (Brislin et al., 2006). Cognitive $\mathrm{CQ}$ is demonstrated, for example, when educators inquire about information needed for teaching and learning, to be most successful in a variety of cultural environments. Motivational CQ refers to the ability to learn about and be able to function in an environment of culture difference. This requires teachers to reflect on their level of interest and motivation to interact with and successfully adapt practices to meet the needs of those that are culturally diverse. Finally, Behavioral CQ refers to the capability to exhibit appropriate verbal and nonverbal interactions with those from different cultures (Ang \& Van Dyne, 2015). These intelligences work together, at different times, in different environments to demonstrate an individual's full CQ, or how one interacts and engages in situations characterized by cultural diversity.

Gelfand et al. (2008) note several advantages in the construct of $\mathrm{CQ}$. First, it offers theoretical coherence within a framework previously characterized by a disconnect of the various elements, here brought together through attention to the 4 dimensional frame. At the same time, this construct offers a more precisely defined concept 
with the inclusion of cognition, motivation and behavior, while purposefully eliminating values or personality, for example. Here, the inclusion of Cognition is significant as a factor that has not received adequate examination in the past. Finally, CQ has a catalog of literature suggesting it works well across disciplines. The CQS has been utilized in a variety of settings outside education. CQ is shown to be useful in evaluating or predicting effective function in contexts from international employment in diplomacy (Shaffer \& Miller, 2008); business (Mannor, 2008; Tay et al., 2008), international nonwork experiences (Traique \& Takeuchi, 2008), multicultural teams (Flaherty, 2008), missionary work (Livermore, 2008), and counseling (Goh, 2012).

Specific to teacher preparation, Cui (2016) utilized the CQS as a predictive assessment among teacher candidates, finding that perceived competence in language or culture, frequency of interaction with diverse populations, and teaching experience were significant predictors of CQ. Our study is intended to further explore the CQS's relevance in teacher education. Mainly, our focus is to assess general areas of strength and weakness across the CQ dimensions that would provide target areas to build from and explicitly address during teacher preparation. Further, we seek to understand what teacher candidates find valuable in the curriculum and experiential opportunities in their preparation programs, as concerns the development of intercultural competence. In particular, we speculated if particular courses, travel abroad, service programs, and/ or working in schools with diverse populations would be cited as influential in developing intercultural competence.

\section{Participants}

This explanatory sequential mixed-methods research included 119 teacher candidates (Tables 1-2), all 18-24 years old, attending three private, liberal arts institutions in the United States. Teacher candidates completed the CQS, provided demographic information and open-ended responses through Survey Monkey. Participants were recruited in teacher education courses during their junior or senior years, from 2014 to 2016. Participants identified almost exclusively as white women (Table 1), consistent with the population of teacher candidates enrolled in the institutions, largely from northeastern and 


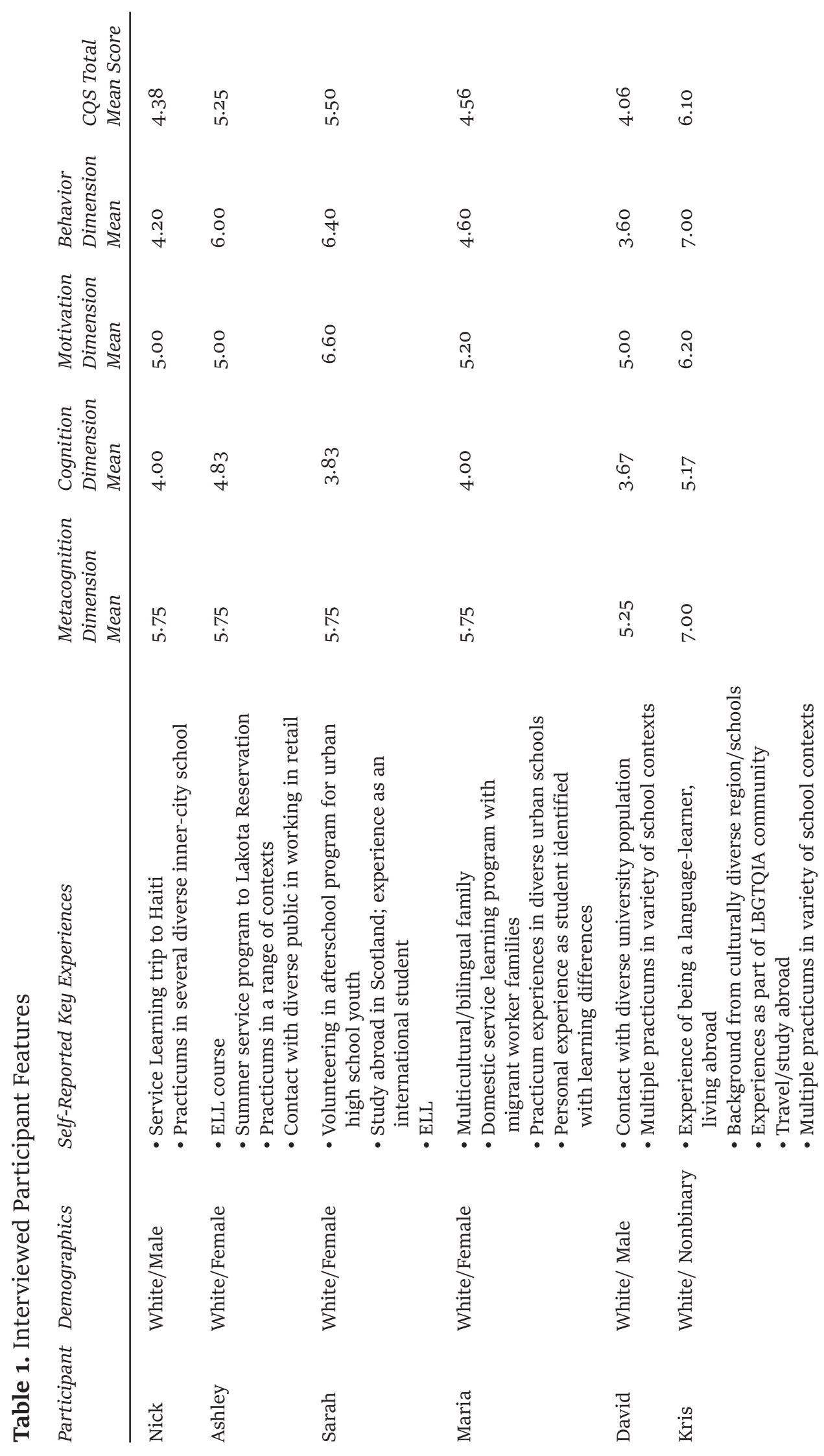




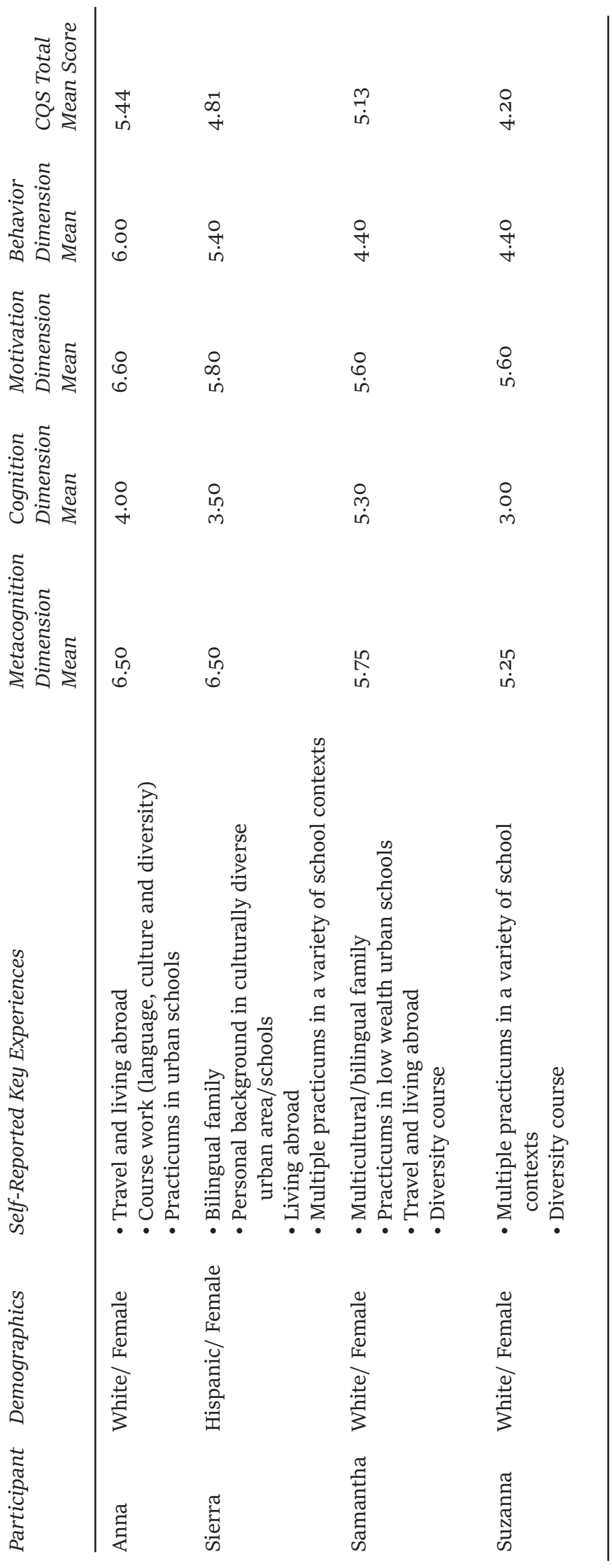


Table 2. Institution and Population Demographics

\begin{tabular}{lcccl} 
& $\begin{array}{c}\text { University } \\
\text { on the Hill }\end{array}$ & $\begin{array}{l}\text { City Side } \\
\text { University }\end{array}$ & $\begin{array}{l}\text { Oakhurst } \\
\text { University }\end{array}$ & $\begin{array}{l}\text { Total/ } \\
\text { \% of Total }\end{array}$ \\
\hline $\begin{array}{l}\text { Race/Ethnicity } \\
\text { American Indian/or Alaskan Native }\end{array}$ & & & 1 & $1(0.84 \%)$ \\
$\begin{array}{l}\text { Asian/Pacific Islander } \\
\text { Black or African American }\end{array}$ & & 3 & 1 & $4(3.36 \%)$ \\
Hispanic & 1 & & 2 & $3(2.52 \%)$ \\
White/Caucasian & 40 & 25 & 43 & $1(0.84 \%)$ \\
Prefer not to report & & & 1 & $1(0.84) \%)$ \\
Gender & 1 & & 5 & $6(5.04 \%)$ \\
Male & 40 & 29 & 43 & $111(93.28 \%)$ \\
Female & & & 1 & $1(0.84 \%)$ \\
Nonbinary identification & & & 1 & $1(0.84 \%)$ \\
Prefer not to report & 41 & 29 & 49 & $n=119$ \\
Total & & & & \\
\hline
\end{tabular}

midAtlantic states. This homogenous group is also representative of the teaching force at large, a troubling pattern that persists in the profession, even as K-12 student diversity increases (Darling-Hammond, 2015). Candidates had completed at least one practicum placement.

In the qualitative component of the study, a purposeful sample of ten teacher candidates, representing a range of international and life experiences, participated in an additional one- to two hour semistructured interview. That is, candidates were chosen who reported across a range of experience (limited to multiple) international travel, study abroad, or service learning, and across a range of CQS mean total score (4.06 to 6.1) with five participants above and below the 5.0 mean total score. Additionally, participants who brought diversity in terms of gender (male) to this portion of the study were given preference.

\section{Data}

The CQS, developed by Ang and Van Dyne (2015) uses a seven-point Likert scale, ranging from strongly-disagree (1) to strongly-agree (7). The survey includes twenty statements with four items in Metacognition, six items in Cognition, five items in Motivation and five items in Behavior. Quantitative data were analyzed using StatPlus for Mac 
(v.6; AnalystSoft) for descriptive and inferential statistics. Additionally, demographic information (age, race, major, minor) was collected. Finally, a series of questions were included to gather data on experiences during teacher preparation, including foreign language experience, study abroad, living abroad, service learning abroad, and recreational travel. All participants had at least one internship experience in a low wealth $\mathrm{K}-12$ school setting as per program requirements.

Ten face-to-face interviews were conducted and transcribed from audio recordings. Initial analysis utilized a constructivist grounded theory approach (Charmaz, 2014) and was informed by consensual qualitative research methods (Hill, 2012). Follow-up questions were exchanged through email for clarification and extrapolation. Four interviews were initially analyzed by three researchers as a group to ensure consistency in code and theme development. A line-by- line analysis was conducted where researchers suggested codes and discussed differences in interpretation. Two additional interviews were reviewed by the same researchers at subsequent intervals to further ensure consistency in use. Interviews were read in the order they were conducted, by institution of the participant, and focusing on the four dimensions of CQS. Finally, readings were conducted for accuracy when quotes were used as examples of supporting or challenging quantitative findings. Codes were reduced to themes, developed from the multiple readings, line-by- line coding, and ongoing iterative analysis. This process led to additional and continuous revisions. Findings generated from the themes were compared to quantitative outcomes for explanatory evidence.

\section{Survey Results}

Aggregated and disaggregated summary statistics for participants' four dimensional scores of the scales (Metacognition, Cognition, Motivation, and Behavior), as well as for the CQS Total Score are reported in Table 3. An analysis of variance (ANOVA) as an omnibus test to identify significant differences between and among groups was followed by Fisher's Least Significant Difference (LSD) test (Table 4), a pairwise comparison technique that uses the mean squared error from the significant ANOVA as its pooled variance estimate (Williams 
Table 3. CQS Dimension and Total Means

\begin{tabular}{lcccc}
$\begin{array}{l}\text { Total Mean } \\
\text { Score }\end{array}$ & $\begin{array}{c}\text { Metacognition } \\
\text { Dimension Mean }\end{array}$ & $\begin{array}{c}\text { Cognition } \\
\text { Dimension Mean }\end{array}$ & $\begin{array}{c}\text { Motivation } \\
\text { Dimension Mean }\end{array}$ & $\begin{array}{c}\text { Behavior } \\
\text { Dimension Mean }\end{array}$ \\
\hline 4.65 & 5.56 & 3.97 & 5.31 & 4.81 \\
$S D=.79$ & $S D=.58$ & $S D=1.02$ & $S D=.96$ & $S D=.79$ \\
\hline
\end{tabular}

Table 4. Fisher LDS Results for Multiple Comparisons ANOVA of Mean CQS Dimension Scores

\begin{tabular}{lccc} 
Dimension Mean Comparisons & Difference & Test Statistic & $p$-Value \\
\hline Behavior vs Cognitive & .844 & 7.766 & $\leq .001^{* * *}$ \\
Behavior vs Metacognitive & -.745 & 6.857 & $\leq .001^{* * *}$ \\
Behavior vs Motivation & -.492 & 4.530 & $\leq .001^{* * *}$ \\
Cognitive vs Metacognition & -1.590 & 14.623 & $\leq .001^{* * *}$ \\
Cognitive vs Motivation & -1.337 & 12.296 & $\leq .001^{* * *}$ \\
Metacognitive vs Motivation & .243 & 2.327 & $.0203^{*}$ \\
\hline
\end{tabular}

${ }^{*} p \leq 0.05 ; * * p \leq .01 ; * * * p \leq .001$

\& Abdi, 2010). For the purposes of this article, we focus on a few key statistical findings. First, we examined descriptive statistics across dimensions, seeking areas of general strength and weakness. Based on the 7-point scale, the average CQS Total Score for all participants was $4.65(S D=.79)$. Among the dimensions, Metacognition (mean = $5.56, S D=.58$ ) and Motivation (mean $=5.31, S D=.96$ ) were relatively higher as compared to Behavior (mean $=4.81, S D=.79$ ) and Cognitive (knowledge) dimension scores (mean $=3.97, S D=1.02$ ). In broad strokes, this pattern remains consistent with relative strengths of each domain in other studies utilizing the CQS (Ang \& Van Dyne, 2015). That is, participants report being aware of cultural differences and highly motivated to interact with those from other cultures but report less confidence in their ability to adapt behavior in intercultural interactions and especially in their knowledge base, as the foundation for intercultural competence. The differences among the various means allowed us to identify an overall range of strengths and weaknesses in the teacher candidates.

Next, regression analysis was used to determine the contribution of a Global Experiences score (the aggregate of reported travel abroad, 
service abroad, living abroad and vacationing abroad from the openresponse items in our survey) and dimensional scores in order to assess for multicollinearity; backward and forward multiple regressions were performed with variable entry criteria $p=.05$, removal criteria $p=.1$, to find best fit for the dependence of the CQS Scores and dimensional scores on global experiences. The partial regression coefficients and significance levels of each of the variables within categories were then analyzed to determine the contributions of each on the Total CQS score, and each of the dimensional scores. We found considerable multicollinearity existed between the categories of global experience (i.e., travel abroad, service learning, living abroad and vacationing abroad), which precipitated the collapse of these items into one variable, which we refer to as Global Experience. Disaggregated analysis identified only Travel Abroad, from among the global experiences, as contributing significantly to a higher total CQS score $(\beta=$ $.5002, p<.001)$. As an aggregated factor, Global Experience was also significant in predicting the Cognitive factor and Total CQS scores ( $\beta$ $=.1884, p<.01)$. Finally, we considered factors that did not demonstrate significant differences in contributing to CQ, including multilingual ability, which suggests that language ability was not important in contributing to a higher total CQS score.

These findings would suggest that a focus on supporting cognitive and behavioral factors, while leveraging motivation and metacognitive awareness would be beneficial to improving overall intercultural competence. In particular, the relatively weak self-reports in cognition and especially knowledge of languages, as the weakest factor within that dimension should be addressed. We were disappointed that findings were less helpful in identifying specific experiences beyond Travel Abroad that significantly influenced intercultural competence. We turned to interpretive data for more explanatory findings.

\section{Qualitative Findings}

Across the three teacher preparation programs there was a variety of required courses, with each institution offering unique opportunities to improve intercultural competence. These experiences fell into three categories: those that targeted preparation in working with diverse 
learners; world language requirements; and courses that provided opportunities for intercultural interactions through travel programs, either domestically or internationally. These are outlined in detail in Table 1. A commonality across programs was noted in terms of placements in schools. Participants from all institutions were required to take part in multiple and lengthy practicums and have experience in classrooms with students from low-wealth and high minority populations. These proved to be important experiences for the candidates.

In considering the use of the CQS, our expectation was that the CQS would reflect useful differences along the four dimensions, which was the case. However, explanatory evidence also left us wondering if the tool itself was not able to reflect more refined subtleties that were critical for use in assessing intercultural competence in teacher candidates. These issues are explored below.

Qualitative findings offered explanatory support for statistical analysis at several levels. First, the interviews highlighted how opportunities differed in their influence as a function of the students' prior experience with diversity and whether candidates were pushed outside of their current comfort zone. Second, we found that multiple experiences, particularly when tied with the act of teaching, were identified as significant in moving candidates toward intercultural competence as an educator. Additionally, interviews provided evidence for which particular program elements were important in influencing intercultural competence. We also found that having language experience was valued, though not necessarily reflected as expected in the CQS results. Below, we address these findings in three areas: moving out of the comfort zone; moving along a trajectory; and identifying experiences significant to growth in cultural competence as it applies to the classroom. Finally, we address how participants experienced and understood language experience as an influence in cultural competence.

\section{Moving Out of the Comfort Zone}

Participants recognized that intercultural competence was dependent on engagement and interactions that pressed them to negotiate through uncertain territory. Ashley stated,

I feel like no one notices [cultural differences] until you've [gone] abroad...or until I worked at North High....I would 
want people in our education program to step outside the bubble. And I think that's through...actually taking them outside the [university] classroom.

In these universities, students' day-to- day life is largely within the sheltered environment of their residential campus. Without further institutional-sponsored experiences working and living in domestic and/or global environments off-campus, the candidates often found themselves among a population that came from similar socio-economic contexts and limited racial and ethnic make-up. The notion of an institutional "bubble" and maintaining cultural consistency came up in students across all institutions. Sarah added, "sometimes I feel like we're sheltered as we're in a nice area of [the city], we're in our little bubble. We like to go to schools that are like us."

Samantha, hundreds of miles away from Sarah, reported growing up in an "extremely small, white, upper-middle class town." She described her growth as a slow and steady progression through her college years, in part because she wanted to stay in an atmosphere where she was already comfortable.

I couldn't go somewhere that was either really big or somewhere vastly different. I just knew [this] for my own comfort level. So then I extended my bubble a little more and I would say that my diversity extended not so much in race or socioeconomic status but more so in...where people come from.

However, both students also chose their institution for the many opportunities offered as they felt ready to challenge themselves. After four practicums in rural and low-wealth schools, and short-term teaching experiences in Barcelona and Malawi, Samantha acknowledged the cultural chasm that too often existed between her life experience and her students, saying, "I think the biggest way [the experiences] impacted me was in knowing that I could not ever...assume that my students know what I'm talking about." Multiple experiences that tested the known life and academic experience of these white middle-class teacher candidates brought awareness of self and the differences that exist between themselves and their students. Nick, in reflecting on his experiences in multiple practicum experiences voiced his recognition that challenges were part of a necessary discomfort: 
You know, there were some tough weeks at Johnson School... .I think it was just good for me to see that is what you just have to face. That's the challenges both teachers and students have to face in the inner city and in areas where there's more ethnically diverse [populations].... It definitely takes a lot of understanding of someone else's culture - of meeting them where they're at.... I am grateful for it because it definitely prepared me for teaching in an inclusive classroom someday, which I know I'm going to have to do.

\section{Moving Along a Trajectory}

Intercultural competence was often addressed relative to past life experiences. For example, candidates viewed the same groups of people as more or less diverse depending on their own past interactions. Pat, from Las Vegas, and Sierra, from Miami, noted that their university lacked what they felt was a truly diverse population. In describing their university, Sierra stated, "There's a lot of white [people] and everyone seems to be very well off." Both felt comfortable in the K-12 classrooms that reflected racial and economic variances that they had experienced in previous academic settings. These candidates' growth in intercultural competence was most influenced by experiences in their semester abroad in Costa Rica. Pat explained,

I've just been really fortunate in having lots of different [cultural interactions]. Lots of kids around me when I was growing up that have been from different places and spoke different languages. And...I felt like if I came across somebody who I knew very little about their culture, I could still find ways of connecting with them. So that's been something that happened in Costa Rica.

From the same institution, Anna and Samantha saw the same university and especially the local schools as very diverse. Both were initially intimidated by racially diverse classrooms, which stood in contrast to their academic experience in almost entirely white K-12 schools. Anna described these classrooms as "very scary, at first," struggling to understand appropriate interactions between teachers 
and students. Both Anna and Samantha, working in the same high school, noted students were "loud," with Samantha adding she initially felt the students were "disrespectful in how they talked to the teacher." Anna noted that interactions with diverse student populations were very important to expanding her cultural awareness and in understanding multiple perspectives. Working in local schools was more influential for Samantha than working with English language learners in Malawi who were "so different than anything I will ever work in again." She found her abroad experience to be more difficult to connect to the working environment she might encounter in the United States, and thus, less useful in terms of connecting to her own career.

In a similar thread, Anna noted both the importance of having a variety of experiences, but also an understanding that each context and culture required different knowledge and interactions that responded to the immediate environment. She said,

I'm glad that I was able to be in a lot of different classrooms throughout my four years before going into my student teaching and going out into the world because I think that did help prepare me. I plan to go to...an inner-city school, I'll probably see a lot more diversity there. Even though these classrooms are pretty diverse, you're still in a more rural area than an inner-city school so, although it's diverse it might be a different type of diverse.

Each of these teacher candidates interacted with similar populations on the same campus and local schools yet experienced their interactions differently in response to past experience. We were struck at how important it was to meet each teacher candidate where they were as they entered the program and offer a range of supported experiences throughout the program sequence for their growth in intercultural competence. Furthermore, experiences abroad, in service learning, or in practicum experiences were significant factors affecting candidates' awareness of their own privilege. As the survey data suggests, appropriate culturally competent behavior - action - was the most problematic dimension to undertake. Interview responses illuminated how some candidates continued to struggle with the shift from a deficit perspective to an asset stance. Candidate growth remained 
dependent on additional learning opportunities and guidance in bridging these experiences to application in K-12 schools.

These responses also made us aware that the items in the CQS data found support in candidates' reports that they wanted more knowledge and saw the need to adapt behaviors - the two lower scoring dimensions. However, the survey did not address elements of culture connected to day-to- day interactions in a classroom and did not seem to capture the need for knowledge across many cultures, which might be represented in schools.

Intercultural Competence and Classroom Experience: Experience That Mattered

We asked participants to describe significant experiences in developing intercultural competence through open-ended survey questions. Additionally, we spoke at length to interviewed participants about which experiences were most influential in developing intercultural competence. Candidates reported that courses focused explicitly on diversity and diverse learners were significant in their learning experience. These courses were sometimes focused on language learners (methods courses for preparing to teach multilingual learners; TSEL courses, etc.,), but also included courses highlighting best practices in working with diverse populations across a semester-long curriculum. Examples included courses that addressed teaching students who were diverse in terms of race, ethnicity, religion, low-wealth communities, country of origin, language, physical abilities, learning needs, or identifying with the LGBTQ + community. Table 1 provides evidence of the frequency with which our interviewed participants mentioned these classes, but equally important was the indication of the genuine significance of courses in promoting intercultural competence. David, for example, said,

I think of our Diverse Learners course.... I went in and ...I had my high school mindset: Kids didn't do the work because they were lazy. Kids didn't, well, they don't do it because they don't care. But if they're diverse learners and you focus on bigger issues, well, maybe he can't do it, or he or she can't read. And that's why they're not doing it. Then you 
really get the bigger picture... those perspectives hit home... I don't want to say it forced a change, but it molded me to a better place to address this.

Teacher candidates consistently noted the influence of their practicum experiences, school internships that were conducted as part of a course, or student teaching experience, as well. Developing cultural awareness and intercultural competence was reported to be particularly notable when teacher candidates had teaching practicums or internships in schools with student populations that reflected life experience different than their own. Experience in multiple practicums across a range of school environments was also consistently cited as being important in developing intercultural competence. Maria noted that these experiences were carried into the classroom, saying,

They have made me aware of the diversities and cultural difference that surround our schools on a daily basis. They have taught me to try and put ourselves into their shoes and empathize with them. This in turn will make us better teachers and make us aware of how they may be feeling. We should try our best every day to welcome them and make them feel comfortable.

However, teacher candidates also added caveats as to the effectiveness of these courses based on when they were offered. Sierra stated, for example, “This [class] means more when you're in the classroom, say close to your methods [course] and student teaching. When you're actually the teacher."

Both domestic service-learning experiences and travel abroad were frequently cited as influential in intercultural competence for those students who had these experiences. These programs were sometimes specifically tied to the teacher education program and experience in schools or university-sponsored. Nick indicated his experience in working with children in Haiti was particularly influential. This was completed during his college career, associated with his church, and chosen because it provided school experience he felt would be applicable in his future teaching career. He noted, 
You can't teach like everyone believes what you believe; everyone practices what you practice.... I mean, in Haiti if you're talking to someone...sometimes they don't look at you. They view that as they're staring you down, but here, if you don't look someone in the eye when they're telling you what to do, it's taken as an insult. But it's just different. I will definitely try my best to be aware people come from a lot of different cultures with a lot of different, just basic practices and beliefs - even down to something we think is trivial as your facial gestures.

The range of opportunities that were available to these candidates across institutions was notable. Across these varied experiences, when candidates indicated that an experience had been particularly influential, they also connected change to having to work outside their comfort zone toward intercultural competence.

The interviews underscored the importance of a range of opportunities for supporting intercultural competence while making connections to teaching and learning explicit. Tutoring programs, community-based afterschool programs, practicum placements in diverse classrooms, and service-learning experiences were cited as influential. While some of these experiences are associated with the teacher preparation program, they were often not requirements, but voluntary undertakings by the candidate. In particular, we were struck by the similarity and intensity with which candidates reflected on domestic community service in similar ways as compared to travel abroad. Experiencing cultural dissonance, language challenges, and developing trusting relationships in these settings pressed students in their intercultural competence. Ashley noted,

One experience I had with diversity is traveling to the Lakota Indian Reservation in South Dakota. It was just a very different experience. For the first time in my life I felt I was in the minority. We pulled up to a gas station and it was a 15-passenger van full of nine white...students and a professor and we were all stared at because we didn't look anything like anybody else. And our cultural experiences were not the same at all. 
These comments support the practice of institutions offering domestic experiences, as well as a menu of international travel options, with the goal of promoting cultural competence with underserved populations at home.

Ashley also underscored that while teacher candidates sought a new cultural experience, they began with limited expectations or understanding of the potential to influence their future professional lives. She stated,

I decided to go on this trip... to be honest with you, I didn't really understand what it was.... I had been in contact with poverty, mostly in city locations. I've done volunteering through [the university] but I had never really experienced a culture that was so different from me.... I wanted a new perspective, so that's why I went.

It is critical preparation programs offer appropriate opportunities and interactions that will optimally provide for growth experiences.

Students also recognized the importance of context. While experiences and a knowledge base might promote awareness and competence, interactions were dependent on their ability to read a situation and respond appropriately in the particular environment and with particular individuals. In responding to whether she felt prepared for teaching students from diverse populations, Ashley offered,

I definitely feel a lot more prepared than I did when I started. Between the classes that I've taken and the experiences that I've had at [the university] I've been in contact with and learned about a lot of different cultures and I definitely feel like I'm as ready as I could be...I think some of it you can only learn from experience. I think the more experience I have in a classroom for extended periods of time, the more I will understand how to interact. I think a lot of situations it's kind of you're not going to know how to handle it until it's actually presented to you.

Ashley reflects the gap that exists and is most especially felt by novice teachers between theoretical knowledge and experience in practice. 
Here again, the active efforts of students to interact in multiple contexts building intercultural competence, reflected on the strength of metacognitive and motivational factors, consistent with the CQS outcomes.

\section{Does Language Experience Matter?}

The qualitative data were also helpful in explaining where no significance was found in the CQS survey data. In particular, we were surprised by the lack of significance in the item Language Experience in predicting higher CQS scores. At first glance, this data suggests that our language requirements or courses were not adequately contributing to intercultural competence. In the interviews, however, students who took part in study abroad, service learning trips that required knowledge of another language, or classroom experiences with multilingual learners reported that they often came to understand the limitations of their knowledge of language, potentially diminishing confidence levels for knowledge of language as it was reflected on the CQS, shown in Table 5. These experiences were still unquestionably influential, however. Sierra noted, "Spanish? I learned more with my homestay family in a few weeks than years in my classes. And I still feel ridiculously ignorant." Kris also dismissed her undergraduate and first-year university language skills in saying,

Not knowing Spanish when I came - I mean I know the basics - I know some Spanish...I had to learn Spanish really quickly. The classes I took [in Costa Rica] were all in Spanish and my professor, my Spanish professor, didn't speak English.... I carried it forward with me as a teacher. I know how it feels to have your teacher not be able to translate for you, so it has helped me as a teacher in learning about how to help students with their language.

Personal struggles, particularly when coupled with academic experiences brought a notable level of understanding and sympathy, along with suggestions of changed behavior as well as dispositional stance. Samantha referenced her experience in two countries where she had expected some language proficiency but was surprised by her own 
Table 5. Language Experiences

\begin{tabular}{lll} 
Participant & $\begin{array}{l}\text { Language Experience } \\
\text { Beyond American English }\end{array}$ & $\begin{array}{l}\text { Language Knowledge } \\
\text { Total Mean COG2 }=3.88\end{array}$ \\
\hline Nick & Limited Spanish & 2.00 \\
Ashley & Limited (High School) Spanish & $\begin{array}{l}\text { Disagree } \\
4.00\end{array}$ \\
Sarah & None reported & Neither agree nor disagree \\
& & 2.00 \\
Maria & Limited Arabic, Limited Spanish & Disagree \\
& & 3.00
\end{tabular}

limitations. She noted the outcome of struggling in situations where she found that she was not comfortable with the local language and the students were not proficient in English.

In Malawi and also in Barcelona - because I didn't speak Catalan and [students] didn't speak English yet, [there was] that language barrier. It taught me about patience, a lot of patience, and to speak slowly.

World language courses were most significant in that they were most usually mentioned when participants noted that they would have liked more experience in this area, in order to feel more culturally competent in the classroom. The candidates did not specifically include on-campus world language courses as particularly influential in building cultural awareness, however. This was true whether or not they were required to have already achieved some level of fluency in a world language. Even those students who were required to have 
additional university courses in a foreign language felt that these requirements were not adequate to respond to the needs of students in their K-12 classrooms. When asked what knowledge she would like to add to become more culturally competent, Sarah identified taking a world language at the college level as her priority in being better prepared for teaching:

I think it would probably be having more knowledge of their languages.... I took Spanish in middle school and high school but I kind of lost it as I came into college.... And it's not just Spanish. I mean there's Middle Eastern languages. There are different Asian languages. There are so many different languages - and I kind of didn't realize how different. I think having more language knowledge would make it easier to communicate with both students and the parents.... I think it would also make sense if the teacher had to learn a little bit of what they spoke, too, because it would give more meaning to them learning English, because the teacher was also learning their language.

Thus, on the one hand, we had candidates who recognized the void left in not having more than one language in which to communicate and on the other hand, we had candidates with world language ability reporting the inadequacy of their functional use of language. Both groups self-reported that their language experience was inadequate, but for different reasons. Those with more experience did not necessarily score higher on the CQS due to their awareness of these limitations. As one of the lower scoring items on the survey, we can conclude that teacher candidates would not only benefit from world language experience, but language experience that is at a more functional standard than is currently provided in the programs where there are such requirements. This difference, however, was not apparent in the quantitative findings.

\section{Limitations}

First and foremost, this research is limited by the homogenous sample population; more work in a full range of institutions with greater 
diversity and numbers is needed. Secondly, while the CQS offered some insight into the difference along the four dimensions, the findings were not clearly connected to teaching and the classroom experience. The findings underscored the need for explicitly connecting experiences provided in preservice preparation to practice, so that knowledge (Cognition) - including language experience - as well as action (Behavior) are thoughtfully identified, discussed, modeled, and applied. While the use of the CQS proved useful in broad strokes, it also had limitations for education and teaching, which might best be addressed through additional items for use in this context, warranting additional study. For example, we would value specific survey items that addressed whether teachers adapted practice based on the population they were teaching, or whether they sought knowledge about additional cultural groups as they were represented in their classroom. We wondered if teachers were aware of the various ways that families might understand expectations and responses from families, which might differ from culture to culture.

\section{Discussion}

In light of the limited research addressing assessment of cultural competence, this study provides evidence that teacher preparation programs should provide opportunities for teacher candidates to explore diverse cultures. It is imperative that teacher candidates step beyond their own cultural space to navigate difficult and perplexing situations (Goh, 2012). As highlighted in other studies utilizing the CQS tool (Ang \& Van Dyne, 2015), teacher candidates are highly motivated to interact with those from other cultures, but often lack confidence in their ability, with least confidence evidenced in behavior. Teacher preparation, like other fields, must address intercultural competence through a variety of measures (Deardorff, 2015). In teacher preparation, this might include coursework, field-work, or immersion experiences.

While the CQS tool had limitations, the quantitative evidence provided a frame for exploration of more targeted qualitative findings. The analysis suggests teacher preparation faculty meet teacher candidates where they as they enter the program. Then faculty should offer a range of supported experiences throughout the program sequence for candidate growth in intercultural competence. For example, 
candidates highlighted how courses focused explicitly on diversity and diverse learners were significant in their learning experience. These courses often included practicum and field-based experiences to bridge theory and practice when working with diverse learners. Beyond coursework, candidates valued opportunities in tutoring programs, community-based after school programs, domestic servicelearning experiences, and travel abroad. Interestingly, candidates found domestic and international experience equally valuable in their development of intercultural competence. Both types of experiences pushed candidates to experience cultural dissonance, language challenges, and a need to develop trusting relationships. Ultimately, the quantitative and qualitative data underscored the importance of a range of opportunities to develop intercultural competence while making connections to teaching and learning explicit.

\section{Implications}

This explanatory, mixed-methods study was undertaken as a means of assessing those elements in teacher preparation that had a positive influence on the development of cultural competence in teacher candidates. The CQS was utilized as a means of evaluating dimensions of metacognition, cognition, motivation and behavior, followed by interviews for further explanatory evidence and understanding of survey responses. This yielded support for teacher preparation including a range of domestic and international opportunities, meaningful contact with diverse populations as part of program requirements, and course content that explicitly addresses cultural competence in the K-12 classroom. Going forward, however, it is also clear that identifying where teacher candidates are in their developmental trajectory will influence their response to these experiences and require ongoing support toward embracing an asset perceptive and enacting culturally competent behavior. Finally, underlying these findings is an implicit and urgent need to continue to prepare all teachers as culturally competent while targeting recruitment efforts of a more diverse population of teacher candidates. 
Conflicting Interests The authors declared no potential conflicts of interest with respect to the research, authorship, and publication of this article.

Funding This work was supported by Elon University, Elon, North Carolina through Faculty Research and Development Grant; School of Education, Office of the Dean funds; Center for Research on Global Engagement Grant.

\section{References}

Alizadeh, S., \& Chavan, M. (2016). Cultural competence dimensions and outcomes: A systematic review of the literature. Health \& Social Care in the Community, 24(6), e117-e130. https://doi.org/10.1111/hsc.12293

Allen, A., \& Hancock, S. D. (2017). Mapping culturally relevant pedagogy into teacher education programs: A critical framework. Teachers College Record, 119(1), 1.

Ang, S., \& Van Dyne, L. (2015). Handbook of cultural intelligence. Routledge.

Ang, S., Van Dyne, L., Koh, C., Ng, K. Y., Templer, K. J., Tay, C., \& Chandrasekar, N. A. (2007). Cultural intelligence: Its measurement and effects on cultural judgment and decision making, cultural adaptation and task performance. Management and Organization Review, 3(3), 335-371. https://doi. org/10.1111/j.1740-8784.2007.00082.x

Aronson, B., \& Laughter, J. (2016). The theory and practice of culturally relevant education: A synthesis of research across content areas. Review of Educational Research, 86(1), 163-206.

Athanases, S. Z., Wahleithner, J. M., \& Bennett, L. H. (2012). Learning to attend to culturally and linguistically diverse learners through teacher inquiry in teacher education. Teachers College Record, 114(7), 1-50.

Baecher, L. (2012). Feedback from the field: What novice preK-12 ESL teachers want to tell TESOL teacher educators. TESOL Quarterly, 46(3), 578-588. https://doi.org/10.1002/tesq.43

Banks, J. A. (2015). Cultural diversity and education: Foundations, curriculum and teaching (6th ed.). Routledge.

Bennett, M. J. (2004). Becoming interculturally competent. In J. Wurtz (Ed.), Toward multiculturalism: A reader in multicultural education (2nd ed., pp. 6277). Intercultural Resource Corporation.

Bok, D. (2009). Our underachieving colleges: A candid look at how much students learn and why they should be learning more. Princeton University Press.

Brislin, R., Worthley, R., \& Macnab, B. (2006). Cultural intelligence: Understanding behaviors that serve people's goals. Group \& Organization Management, 31(1), 40-55.

Butin, D. (2010). Service-learning in theory and practice: The future of community engagement in higher education. Springer. 
Carreira, M., \& Kagan, O. (2018). Heritage language education: A proposal for the next 50 years. Foreign Language Annals, 51(1), 152-168. https://doi. org/10.1111/flan.12331

Charmaz, K. (2014). Constructing grounded theory (2nd ed.). Sage Publication Ltd.

Cochran-Smith, M., Ell, F., Grudnoff, L., Haigh, M., Hill, M., \& Ludlow, L. (2016). Initial teacher education: What does it take to put equity at the center? Teaching and Teacher Education, 57, 67-78. https://doi.org/10.1016/j. tate.2016.03.006

Cole, E. R., Case, K. A., Rios, D., \& Curtin, N. (2011). Understanding what students bring to the classroom: Moderators of the effects of diversity courses on student attitudes. Cultural Diversity and Ethnic Minority Psychology, 17(4), 397-405. https://doi.org/10.1037/a0025433

Creswell, J. W., \& Clark, V. L. P. (2017). Designing and conducting mixed methods research (3rd ed.). Sage Publications Ltd.

Cui, X. (2016). A study of factors influencing students' intercultural competence. Journal of Language Teaching and Research, 7(3), 433-439. https://doi. org/10.17507/jltr.0703.01

Darling-Hammond, L. (2015). The flat world and education: How America's commitment to equity will determine our future. Teachers College Press.

Deardorff, D. K. (2006). Identification and assessment of intercultural competence as a student outcome of internationalization. Journal of Studies in International Education, 1O(3), 241-266. https://doi.org/10.1177/1028315306287002

Deardorff, D. K. (Ed.). (2009). The SAGE handbook of intercultural competence. Sage.

Deardorff, D. K. (2011). Assessing intercultural competence. new directions for institutional research (149) 65-79. Wiley Periodicals, Inc.

Deardorff, D. K. (2015). Demystifying outcomes assessment for international educators: A practical approach. Stylus Publishing, LLC.

Deardorff, D. K., \& Arasaratnam-Smith, L. A. (Eds.). (2017). Intercultural competence in higher education: International approaches, assessment and application. Routledge.

Fantini, A. (2009). Assessing intercultural competence: Issues and tools. In D. K. Deardorff (Ed.), The SAGE handbook of intercultural competence. Sage.

Flaherty, J. (2008). The effects of cultural intelligence on team member acceptance and integration in multinational teams. In S. Ang \& L. Van Dyne (Eds.), Handbook of cultural intelligence: Theory, measurement, and applications (pp. 192-205). M. E. Sharpe.

Gay, G. (2018). Culturally responsive teaching: Theory, research, and practice. Teachers College Press.

Gelfand, M. J., Imai, L., \& Fehr, R. (2008). Thinking intelligently about cultural intelligence. In Handbook on cultural intelligence: Theory, measurement and applications (pp. 375-388). M. E. Sharpe. 
Goh, M. (2012). Teaching with cultural intelligence: Developing multiculturally educated and globally engaged citizens. Asia Pacific Journal of Education, 32(4), 395-415. https://doi.org/10.1080/02188791.2012.738679

Hansen, D. T. (2017). The teacher and the world: A study of cosmopolitanism as education. Routledge.

He, Y., Lundgren, K., \& Pynes, P. (2017). Impact of short-term study abroad program: Inservice teachers' development of intercultural competence and pedagogical beliefs. Teaching and Teacher Education, 66, 147-157. https://doi. org/10.1016/j.tate.2017.04.012

Hill, C. E. (2012). Consensual qualitative research: A practical resource for investigating social science phenomena. American Psychological Association.

Kahn, H. E., \& Agnew, M. (2017). Global learning through difference: Considerations for teaching, learning, and the internationalization of higher education. Journal of Studies in International Education, 21(1), 52-64.

Kohli, R., Pizarro, M., \& Nevárez, A. (2017). The "new racism" of K-12 schools: Centering critical research on racism. Review of Research in Education, 41(1), 182-202. https://doi.org/10.3102/0091732X16686949

Kopish, M. A. (2016). Preparing globally competent teacher candidates through cross-cultural experiential learning. Journal of Social Studies Education Research, 7(2), Retrieved from https://dergipark.org.tr/en/pub/jsser/ issue/26846/282299

Ladson-Billings, G. (2004). New directions in multicultural education. Handbook of Research on Multicultural Education, 2, 50-65.

Ladson-Billings, G. (2014). Culturally relevant pedagogy 2.0: A.k.a. The Remix. Harvard Educational Review, 84(1), 74-84. https://doi.org/10.17763/ haer.84.1.p2rj131485484751

Lindahl, K. M., Tomas, Z., Farrelly, R., \& Krulatz, A. (2018). The value of servicelearning in L2 teacher preparation: Engaging in diverse contexts. In Handbook of research on service-learning initiatives in teacher education programs (pp. 103-124). IGI Global.

Livermore, D. (2008). Cultural intelligence and short-term missions: The phenomenon of the fifteen-year-old missionary. In S. Ang \& L. Van Dyne (Eds.), Handbook of cultural intelligence: Theory, measurement, and applications (pp. 271-285). M. E. Sharpe.

Mannor, M. J. (2008). Top executives and global leadership: At the intersection of cultural intelligence and strategic leadership theory. In S. Ang \& L. Van Dyne (Eds.), Handbook of cultural intelligence: Theory, measurement, and applications (pp. 71-90). M. E. Sharpe.

McKim, C. A. (2017). The value of mixed methods research: A mixed methods study. Journal of Mixed Methods Research, 11(2), 202-222.

Merryfield, M. M., Lo, J. T.-Y., Po, S. C., \& Kasai, M. (2008). Worldmindedness: Taking off the blinders. Journal of Curriculum and Instruction, 2(1), 6-20. https://doi.org/10.3776/joci.2008.v2n1p6-20 
Samson, J. F., \& Collins, B. A. (2012). Preparing all teachers to meet the needs of English language learners: Applying research to policy and practice for teacher effectiveness. Center for American Progress.

Scanlan, M., \& López, F. A. (2014). Leadership for culturally and linguistically responsive schools: Routledge.

Shaffer, M., \& Miller, G. (2008). Cultural intelligence: A key to success factor for expatriates. In S. Ang \& L. Van Dyne (Eds.), Handbook of cultural intelligence: Theory, measurement, and applications (pp. 107-125). M.E. Sharpe.

Spitzberg, B. H., \& Changnon, G. (2009). Conceptualizing intercultural competence. In The SAGE handbook of intercultural competence (pp. 2-52). Sage.

Tay, C., Westman, M., \& Chia, A. (2008). Antecedents and consequences of cultural intelligence among short-term business travelers. In S. Ang \& L. Van Dyne (Eds.), Handbook of cultural intelligence: Theory, measurement, and applications (pp. 126-144). M. E. Sharpe.

Tomalin, B., \& Stempleski, S. (2013). Cultural awareness. Oxford University Press.

Traique, I., \& Takeuchi, R. (2008). Developing cultural intelligence: The roles of international nonwork experiences. In S. Ang \& L. Van Dyne (Eds.), Handbook of cultural intelligence: Theory, measurement, and applications (pp. 41-55). M. E. Sharpe.

Tran, Y. (2015). ESL pedagogy and certification: Teacher perceptions and efficacy. Journal of Education and Learning, 4(2), 28-42. https://doi.org/10.5539/jel. v4n2p28

Twombly, S. B., Salisbury, M. H., Tumanut, S. D., \& Klute, P. (2012). Study abroad in a new global century-renewing the promise, refining the purpose. ASHE Higher Education Report, 38(4), 1-152.

Williams, L. J., \& Abdi, H. (2010). Fisher's least significant difference (LSD) test. In N. Salkind (Ed.), Encyclopedia of research design (Vol. 218, pp. 840-853). Sage. https://doi.org/doi.org/10.4135/9781412961288.n154

\section{The authors}

Joan Barnatt, Ph.D., is an associate professor of Education at Elon University in Elon, North Carolina. Her research interests include global and international education, and teacher preparation, especially for teachers of language learners.

Lisa Andries D’Souza, Ph.D., is an associate professor in the Education Department at Assumption College in Worcester, MA. Her research interests include teacher preparation, history and social science education, and middle-level teacher education. 
Ann Marie Gleeson, Ph.D., is the History and Social Science test development coordinator for the Massachusetts Department of Elementary and Secondary Education. Her research interests include social studies education, assessment, and teacher preparation.

Kara Mitchell Viesca, Ph.D., is an associate professor of Teaching, Learning and Teacher Education at the University of Nebraska-Lincoln. Her scholarship focuses on advancing equity in the policy and practice of educator development, particularly for teachers of multilingual learners.

Jessica J. Wery, Ph.D., is an adjunct professor at North Carolina State University, Chapel Hill, NC. Her research interests lie in special education and the education of exceptional children. 